\title{
Numerical Simulation to Air Pollution Emission Control near an Industrial Zone
}

\author{
Pravitra Oyjinda ${ }^{1,2}$ and Nopparat Pochai ${ }^{1,2}$ \\ ${ }^{1}$ Department of Mathematics, Faculty of Science, King Mongkut's Institute of Technology Ladkrabang, Bangkok 10520, Thailand \\ ${ }^{2}$ Centre of Excellence in Mathematics, CHE, Si Ayutthaya Rd., Bangkok 10400, Thailand
}

Correspondence should be addressed to Nopparat Pochai; nop_math@yahoo.com

Received 9 June 2017; Revised 16 August 2017; Accepted 24 August 2017; Published 2 October 2017

Academic Editor: Rehana Naz

Copyright (C) 2017 Pravitra Oyjinda and Nopparat Pochai. This is an open access article distributed under the Creative Commons Attribution License, which permits unrestricted use, distribution, and reproduction in any medium, provided the original work is properly cited.

\begin{abstract}
A rapid industrial development causes several environment pollution problems. One of the main problems is air pollution, which affects human health and the environment. The consideration of an air pollutant has to focus on a polluted source. An industrial factory is an important reason that releases the air pollutant into the atmosphere. Thus a mathematical model, an atmospheric diffusion model, is used to estimate air quality that can be used to describe the sulfur dioxide dispersion. In this research, numerical simulations to air pollution measurement near industrial zone are proposed. The air pollution control strategies are simulated to achieve desired pollutant concentration levels. The monitoring points are installed to detect the air pollution concentration data. The numerical experiment of air pollution consisted of different situations such as normal and controlled emissions. The air pollutant concentration is approximated by using an explicit finite difference technique. The solutions of calculated air pollutant concentration in each controlled and uncontrolled point source at the monitoring points are compared. The air pollutant concentration levels for each monitoring point are controlled to be at or below the national air quality standard near industrial zone index.
\end{abstract}

\section{Introduction}

Nowadays, the air pollution is a major problem in the world because industrial areas grew rapidly. The pollution emission of factories into the atmosphere will have an effect on human health and the environment. The purpose of this research is to study the problem of air pollution emission control. The approximate solution is considered by using the atmospheric diffusion model.

In [1], an atmospheric transport diffusion model with wind velocity profile and diffusion coefficient was considered to study the system of delayed removal. The air pollutant was emitted from a line source with the dry deposition on the ground. The fractional step method was used for computing the air pollutant concentration. In [2], the atmospheric diffusion equation with multiple sources and wind speed and eddy diffusivities was studied to derive the analytical solutions for many boundary condition types. The Green's function concept was used to solve the threedimensional analytical solutions everywhere in the region of interest. In [3], the finite difference method was used for solving the two-dimensional advection-diffusion equation with a point source. In [4], a time dependent mathematical model of primary and secondary pollutants was studied for approximating the concentration from area source. The wind velocities and eddy diffusion coefficients are considered to be the realistic value. The researchers solved the problem by using Crank-Nicolson implicit finite difference technique and upwind difference scheme which is applied to the diffusion term. In [5], the researchers studied the three-dimensional mathematical model for the sulfur dioxide concentration without obstacles domain.

In [6], the researchers studied a three-dimensional convection-diffusion-reaction equation for sulfur and nitrogen oxides. The model was solved by using a high order accurate time-stepping discretization scheme as Lax and Wendroff technique. A steady state two-dimensional mathematical model of urban heat island was used to describe the dispersion of air pollution with mesoscale wind velocity and meteorological parameters in [7]. The genesis of air pollution 
was area source emitted from the ground. The removal mechanism was considered by wet and dry depositions. The concentration of air pollutant was approximated by using Crank-Nicolson implicit method. In [8], the mass transport model was considered to simulate the smoke dispersion from one and two point sources with obstacle domain. The model consisted of three equations: a stream function, vorticity, and convection-diffusion equation. The results of air pollution in two-dimensional space and one-dimensional time were calculated by using the finite element method and finite difference method, respectively. In [9], the two-dimensional smoke dispersion model was studied in the cases of two and three point sources with obstacles domain. In [10], the researchers studied a spatial autoregressive model for sulfur dioxide concentration. The evaluation of sulfur dioxide was assessed by the land use regression (LUR) model. The mobile monitoring was used for collecting concentration data in Hamilton, Ontario, Canada.

In [11], the dispersion of primary pollutant was studied in a two-dimensional air pollution model with mesoscale wind. The primary air pollutant was emitted from an area source and the researchers considered removal mechanisms such as dry deposition, gravitational settling, and chemical reaction. The two-dimensional advection-diffusion models of the primary and secondary pollutants are presented in [12]. The researchers studied the air pollutant emitted from area source with removal mechanisms by considering point source on the boundary. The Crank-Nicolson implicit method is used as the finite difference technique in $[11,12]$. The design and application of Atmospheric Evaluation and Research Integrated model for Spain (AERIS) are proposed in [13]. The air pollutant concentrations of $\mathrm{NO}_{2}, \mathrm{O}_{3}, \mathrm{SO}_{2}, \mathrm{NH}_{3}$, and PM as a reaction to emission variations of significant sectors in Spain are obtained by AERIS. The results of the model are estimated by using transfer matrices based on an air quality modelling system (AQMS). The system consists of the Weather Research and Forecast (WRF), Sparse Matrix Operator Kernel Emissions (SMOKE), and Community Multiscale Air Quality (CMAQ) models. In [14], the researchers studied air flow and dispersion of pollutant in urban street canyons. The Computational Fluid Dynamics (CFD) were simulated by using Large Eddy Simulation (LES). A velocity comparison between Fluctuating Wind Boundary Conditions (FWBC) and Steady Wind Boundary Conditions (SWBC) was investigated. In [15], the researchers used the three-dimensional air quality model. The considered domain contained three buildings (obstacles) divided into two zones: a factory zone and a residential zone. The modifications of atmospheric stability classes and wind velocities from multiple point sources were also analyzed. The approximate solutions in $[5,9,15]$ were solved by using the fractional step method.

A numerical model for air pollution emission control problem with the uniform wind velocities and constant diffusion coefficients is proposed. In this research, the atmospheric diffusion equation is solved by using the finite difference method. This study analyzed the ambient air quality standard of sulfur dioxide that refers to the quantity of sulfur dioxide concentration in clean air.

\section{Governing Equation}

2.1. The Atmospheric Diffusion Equation. The diffusion model is used to represent the behavior of air pollutant concentration in industrial areas. The Gaussian plume idea is used as the governing equation. It is the well-known atmospheric diffusion equation. We introduced the three-dimensional advection-diffusion equation as follows:

$$
\begin{aligned}
\frac{\partial c}{\partial t} & +u \frac{\partial c}{\partial x}+v \frac{\partial c}{\partial y}+w \frac{\partial c}{\partial z} \\
& =k_{x} \frac{\partial^{2} c}{\partial x^{2}}+k_{y} \frac{\partial^{2} c}{\partial y^{2}}+k_{z} \frac{\partial^{2} c}{\partial z^{2}}+S+R
\end{aligned}
$$

where $c=c(x, y, z, t)$ is the air pollutant concentration at $(x, y, z)$ and time $t\left(\mathrm{~kg} / \mathrm{m}^{3}\right), u, v$, and $w$ are the wind velocity components $(\mathrm{m} / \mathrm{s})$ in $x$-, $y$-, and $z$-direction, respectively $(\mathrm{m} / \mathrm{s}), k_{x}, k_{y}$, and $k_{z}$ are the diffusion coefficients in $x-$, $y$-, and $z$-direction, respectively $\left(\mathrm{m}^{2} / \mathrm{s}\right), S$ is the growth of pollutant rate due to sources $\left(\mathrm{sec}^{-1}\right)$, and $R$ is the decaying of pollutant rate due to sinks $\left(\mathrm{sec}^{-1}\right)$.

In this research, we considered only the primary pollutant concentration as sulfur dioxide. The chemical formula is $\mathrm{SO}_{2}$. The assumption of (1) defined that the advection and diffusion in $y$-direction are laterally averaged. By the assumption, we can also eliminate the term in $y$-direction. Therefore, the primary pollutant equation can be written as

$$
\frac{\partial c}{\partial t}+u \frac{\partial c}{\partial x}+w \frac{\partial c}{\partial z}=k_{x} \frac{\partial^{2} c}{\partial x^{2}}+k_{z} \frac{\partial^{2} c}{\partial z^{2}}+S+R
$$

The initial condition is assumed under the cold start assumption. That is,

$$
c(x, z, 0)=0 \text {, }
$$

for all $x>0$ and $z>0$. The boundary conditions assumed that

$$
\begin{aligned}
& \frac{\partial c}{\partial x}(0, z, t)=\frac{\partial c}{\partial x}(L, z, t)=0, \\
& \frac{\partial c}{\partial z}(x, H, t)=0, \\
& \frac{\partial c}{\partial z}(x, 0, t)=v_{d} c,
\end{aligned}
$$

for all $t>0$, where $L$ is the length of the domain in $x$ direction, $H$ is the height of the inversion layer, and $v_{d}$ is the dry deposition velocity of the primary pollutant $(\mathrm{m} / \mathrm{s})$. Sulfur dioxide deposition velocity can be related to a diffusion coefficient $k_{z}$ which is assumed to be an irreversible process.

In Figure 1, model of air pollution emission control problem is presented. This research was designed to study the behavior of dispersion and effect of dispersion concentration near the industrial zone. The four monitoring points are set far away from the source. Each monitoring point is called $M 1, M 2, M 3$, and $M 4$ respectively. In Figure 2, the considered domain for the numerical experiment is shown. Let the height 


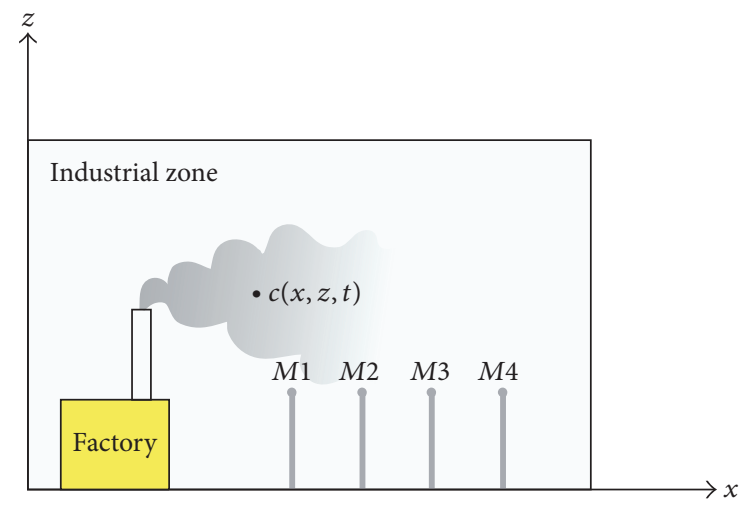

FIGURE 1: Model of air pollution emission control problem.

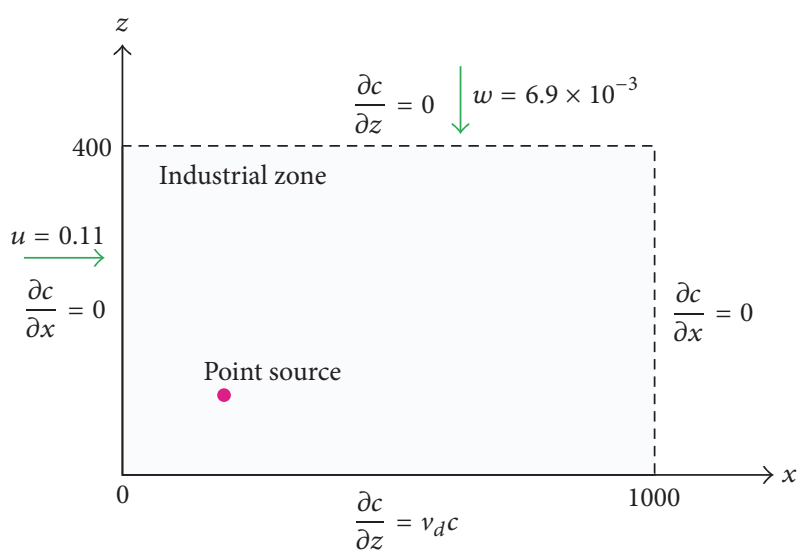

FIGURE 2: Domain of approximate solutions.

of point source be $z=h_{s} \mathrm{~m}$. The wind is stable in $x$ - and $z$ axis. The concentrations of air pollutant are emitted directly from a continued point source (chimney) from industrial factory. The air pollutants are absorbed from the chemical reaction on the ground.

2.2. The Nondimensional Form Equation. From (2), we present the nondimensional form of air pollution. The following dimensionless variables are defined by $C=c / c_{\max }, X=x / l_{x}$, $Z=z / l_{z}, T=t / t_{\max }, D_{x}=k_{x} / l_{x} u_{\max }, D_{z}=k_{z} / l_{z} u_{\max }$, $U=u / u_{\max }$, and $W=\beta w_{\max } / u_{\max }$ when $\beta=w / w_{\max }$. We let $c_{\max }=\max \left\{c(x, z, t): 0 \leq x \leq L, 0 \leq z \leq H, 0 \leq t \leq t_{\max }\right\}$, $u_{\max }=\max \left\{u(x, z, t): 0 \leq x \leq L, 0 \leq z \leq H, 0 \leq t \leq t_{\max }\right\}$, and $w_{\max }=\max \{w(x, z, t): 0 \leq x \leq L, 0 \leq z \leq H, 0 \leq t \leq$ $\left.t_{\max }\right\}$, and $t_{\max }$ is a stationary time. Therefore, the nondimensional atmospheric diffusion equation can be rearranged to give

$$
\begin{aligned}
& \frac{1}{S t} \frac{\partial C}{\partial T}+U \frac{\partial C}{\partial X}+W \frac{\partial C}{\partial Z} \\
& \quad=D_{x} \frac{\partial^{2} C}{\partial X^{2}}+D_{z} \frac{\partial^{2} C}{\partial Z^{2}}+S-k_{p} C
\end{aligned}
$$

where $l=\max \left\{l_{x}, l_{z}\right\}, S t=t_{\max } u_{\max } / l$, and $k_{p}$ is the chemical interaction rate of primary pollutant equation. For the nondimensional form of initial condition, it is assumed that

$$
C(X, Z, 0)=0 \text {, }
$$

for all $X>0$ and $0 \leq Z \leq H$. For the nondimensional form of boundary, it is assumed that

$$
\begin{aligned}
& \frac{\partial C}{\partial X}(0, Z, T)=\frac{\partial C}{\partial X}(L, Z, T)=0, \\
& \frac{\partial C}{\partial Z}(X, H, T)=0, \\
& \frac{\partial C}{\partial Z}(X, 0, T)=v_{d} C,
\end{aligned}
$$

for all $T>0$.

\section{Numerical Method}

The prediction of primary pollutant from a stationary source can be calculated to solve the air pollution problem in the industrial areas. In (5), we get the concentration of $C$ at each time $T_{n+1}$ from $T_{n}=n \Delta T, n=0,1,2, \ldots, P$, when $\Delta T$ is a time increment. The solution of sulfur dioxide concentration at $(X, Z, T)$ is denoted by $C\left(X_{i}, Z_{j}, T_{n}\right)=C_{i, j}^{n}$. The considered domain is meshed by the grid spacing $\Delta X$ and $\Delta Z$ where $X_{i}=i \Delta X, i=0,1,2, \ldots, N$, and $Z_{j}=j \Delta Z$, $j=0,1,2, \ldots, M$. The finite difference method is chosen as proper equipment for estimating solutions. The method refers to the nondimensional model, for which we use the forward time central space (FTCS) scheme. In the transient term, we used the forward difference for

$$
\frac{\partial C}{\partial T}=\frac{C_{i, j}^{n+1}-C_{i, j}^{n}}{\Delta T} .
$$

The advection and diffusion terms are substituted by using the centered difference in space by

$$
\begin{aligned}
\frac{\partial C}{\partial X} & =\frac{C_{i+1, j}^{n}-C_{i-1, j}^{n}}{2 \Delta X}, \\
\frac{\partial C}{\partial Z} & =\frac{C_{i, j+1}^{n}-C_{i, j-1}^{n}}{2 \Delta Z}, \\
\frac{\partial^{2} C}{\partial X^{2}} & =\frac{C_{i+1, j}^{n}-2 C_{i, j}^{n}+C_{i-1, j}^{n}}{(\Delta X)^{2}}, \\
\frac{\partial^{2} C}{\partial Z^{2}} & =\frac{C_{i, j+1}^{n}-2 C_{i, j}^{n}+C_{i, j-1}^{n}}{(\Delta Z)^{2}},
\end{aligned}
$$

respectively. The formula of (5) becomes

$$
\begin{aligned}
& \frac{1}{S t}\left(\frac{C_{i, j}^{n+1}-C_{i, j}^{n}}{\Delta T}\right)+U\left(\frac{C_{i+1, j}^{n}-C_{i-1, j}^{n}}{2 \Delta X}\right) \\
& \quad+W\left(\frac{C_{i, j+1}^{n}-C_{i, j-1}^{n}}{2 \Delta Z}\right) \\
& =D_{x}\left(\frac{C_{i+1, j}^{n}-2 C_{i, j}^{n}+C_{i-1, j}^{n}}{(\Delta X)^{2}}\right) \\
& \quad+D_{z}\left(\frac{C_{i, j+1}^{n}-2 C_{i, j}^{n}+C_{i, j-1}^{n}}{(\Delta Z)^{2}}\right)+S-k_{p} C_{i, j}^{n} .
\end{aligned}
$$


Thus, the finite difference form of the advection-diffusion equation becomes

$$
\begin{aligned}
C_{i, j}^{n+1}= & \left(d_{x}-A_{x}\right) C_{i+1, j}^{n}+\left(d_{x}+A_{x}\right) C_{i-1, j}^{n} \\
& +\left(1-2 d_{x}-2 d_{z}-k_{p} \Delta T(S t)\right) C_{i, j}^{n} \\
& +\left(d_{z}+A_{z}\right) C_{i, j-1}^{n}+\left(d_{z}-A_{z}\right) C_{i, j+1}^{n} \\
& +S t(\Delta T) S,
\end{aligned}
$$

where $A_{x}=\operatorname{St}(\Delta T) U / 2 \Delta X, A_{z}=\operatorname{St}(\Delta T) W / 2 \Delta Z, d_{x}=$ $\operatorname{St}(\Delta T) D_{x} /(\Delta X)^{2}$, and $d_{z}=\operatorname{St}(\Delta T) D_{z} /(\Delta Z)^{2}$.

\section{Air Pollution Controlled Simulations}

The experiment analyzed the action of air pollution with the volume of sulfur dioxide emission around an industrial zone. We will simulate the air pollution control situation in three cases. For the first simulation, an industrial factory released continued air pollutant from a chimney without emission control system. For the second and the third simulations, the factory will discharge the sulfur dioxide, which is controlled by the national air quality index.

\subsection{Simulation 1: Air Pollution Emission without Controlled} System. In the first simulation, the two-dimensional advection-diffusion equation (5) with a domain of interest of $1000 \times 400 \mathrm{~m}^{2}$ is considered. The wind velocities in $x$ - and $z$-direction are assumed to be 0.11 and $6.9 \times 10^{-3} \mathrm{~m} / \mathrm{s}$, respectively. The sulfur dioxide is released at the chimney height $h_{s}=75 \mathrm{~m}$ at coordinate $(100,75)(\mathrm{m}, \mathrm{m})$. The released pollutant concentration is $0.75 \mathrm{sec}^{-1}$. The diffusion coefficients in $x$ - and $z$-direction are 2 and $0.45 \mathrm{~m}^{2} / \mathrm{s}$, respectively. The grid spacing is $\Delta x=\Delta z=25 \mathrm{~m}$ and time interval is $72 \mathrm{sec}$. This simulation is solved by using FTCS in (16) with the initial and boundary conditions (6)-(9). The numerical solutions of air pollutant concentration when 58 minutes and 1 hour and 36 minutes have passed are shown in Figures 3 and 4 , respectively. The monitoring points are aligned along 200, 300, 400, and $500 \mathrm{~m}$ in the same height, $50 \mathrm{~m}$. The comparison of concentrations of different distances is presented in Figure 5.

4.2. Simulation 2: Air Pollution Emission Controlled by following the National Air Quality Standard $\left(3 \times 10^{-7} \mathrm{~kg} / \mathrm{m}^{3}\right)$. In the second simulation, the two-dimensional advection-diffusion equation (5) with a domain of interest of $1000 \times 400 \mathrm{~m}^{2}$ is considered. The wind velocities in $x$ - and $z$-direction are assumed to be 0.11 and $6.9 \times 10^{-3} \mathrm{~m} / \mathrm{s}$, respectively. The sulfur dioxide is released at the chimney height $h_{s}=75 \mathrm{~m}$ at the coordinate $(100,75)(\mathrm{m}, \mathrm{m})$. The released pollutant concentration is $0.75 \mathrm{sec}^{-1}$. The diffusion coefficients in $x$ - and $z$ direction are 2 and $0.45 \mathrm{~m}^{2} / \mathrm{s}$, respectively. The grid spacing is $\Delta x=\Delta z=25 \mathrm{~m}$ and time interval is $72 \mathrm{sec}$. In this simulation, the sulfur dioxide is released by following the United States Environmental Protection Agency (USEPA) air quality standard [16], $3 \times 10^{-7} \mathrm{~kg} / \mathrm{m}^{3}$. If the approximated pollutant concentration at a monitoring point becomes higher than the

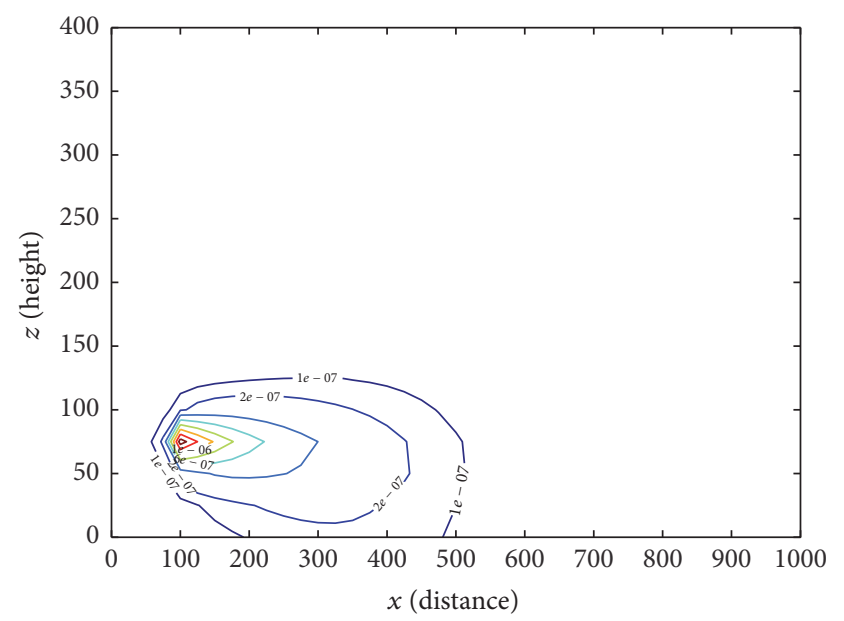

(C) Concentration of $\mathrm{SO}_{2}$

FIGURE 3: The concentration levels of air pollution after 58 minutes have passed without control system.

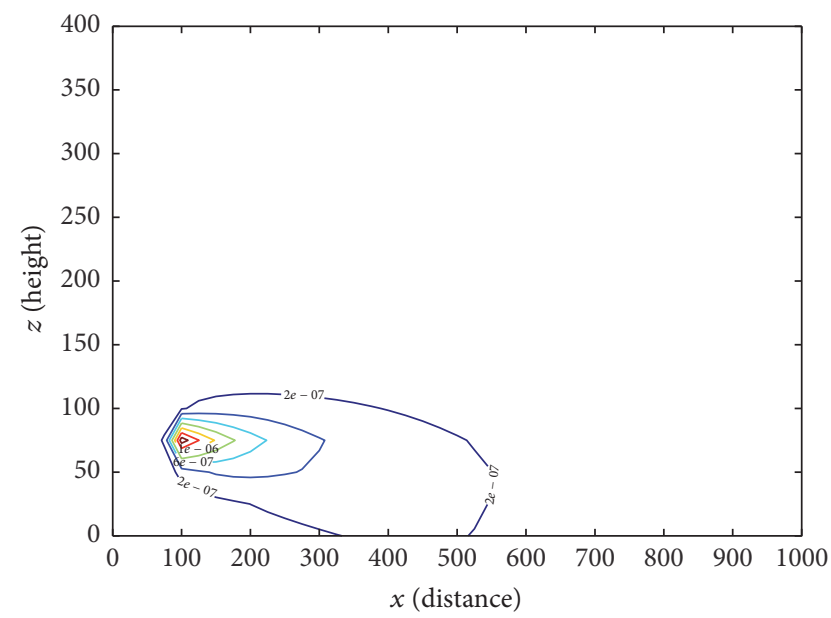

a) Concentration of $\mathrm{SO}_{2}$

FIGURE 4: The concentration levels of air pollution after 1 hour and 36 minutes have passed without control system.

air quality standard, then the chimney will be shut down and wait until the concentration goes below $1.5 \times 10^{-7} \mathrm{~kg} / \mathrm{m}^{3}$. If the pollutant concentration at all monitoring points is below a half of the air quality standard, the chimney will be opened again. The air pollution emission will be following these processes. This example is solved by using FTCS in (16) with the initial and boundary conditions (6)-(9). The results of air pollution emission control are demonstrated as the contour lines of sulfur dioxide concentration in Figures 6 and 7. The concentration of air pollution in the different distance is shown in Figure 8.

4.3. Simulation 3: Air Pollution Emission Controlled by following the National Air Quality Standard $\left(1.5 \times 10^{-7} \mathrm{~kg} / \mathrm{m}^{3}\right)$. In the third simulation, the two-dimensional advectiondiffusion equation (5) with a domain of interest of $1000 \times$ $400 \mathrm{~m}^{2}$ is considered. The wind velocities in $x$ - and $z$-direction 


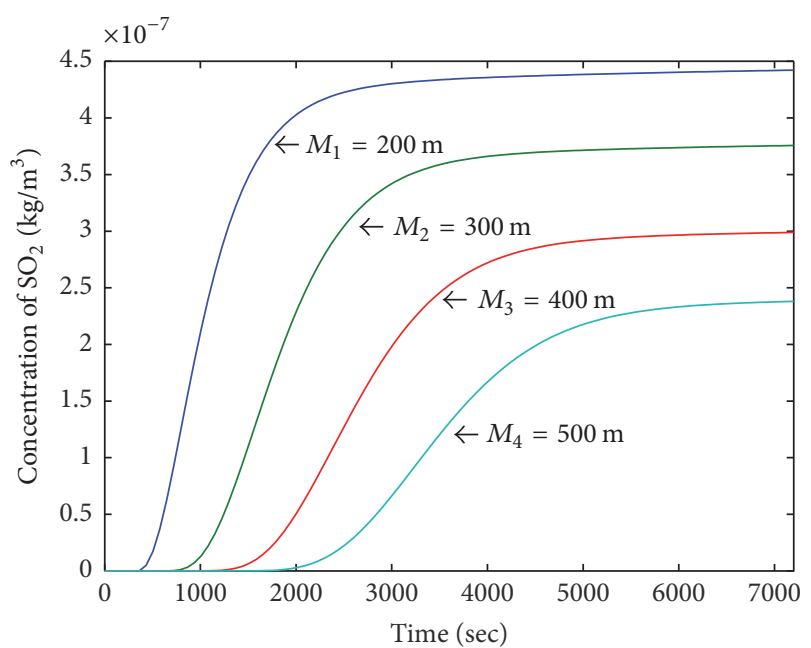

FIGURE 5: The concentration of air pollution with the different monitoring point at $z=50 \mathrm{~m}$ without control system.

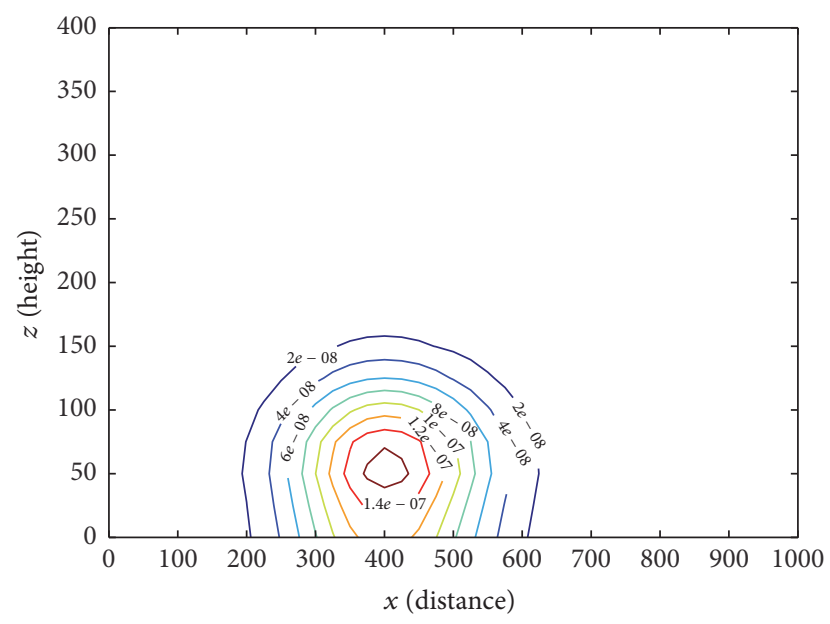

FIGURE 6: The concentration levels of air pollution after 58 minutes have passed which are controlled by air quality standard $(3 \times$ $10^{-7} \mathrm{~kg} / \mathrm{m}^{3}$ ).

are assumed to be 0.11 and $6.9 \times 10^{-3} \mathrm{~m} / \mathrm{s}$, respectively. The sulfur dioxide is released at the chimney height $h_{s}=75 \mathrm{~m}$ at the coordinate $(100,75)(\mathrm{m}, \mathrm{m})$. The released pollutant concentration is $0.75 \mathrm{sec}^{-1}$. The diffusion coefficients in $x$ and $z$-direction are 2 and $0.45 \mathrm{~m}^{2} / \mathrm{s}$, respectively. The grid spacing is $\Delta x=\Delta z=25 \mathrm{~m}$ and time interval is $72 \mathrm{sec}$. In this simulation, the sulfur dioxide is released by following the USEPA air quality standard, $1.5 \times 10^{-7} \mathrm{~kg} / \mathrm{m}^{3}$. If the approximated pollutant concentration at a monitoring point becomes higher than the air quality standard, then the chimney will be shut down and wait until the concentration goes below $1.0 \times 10^{-7} \mathrm{~kg} / \mathrm{m}^{3}$. If the pollutant concentration at all monitoring points is below a third of the air quality standard, the chimney will be opened again. The air pollution emission will be following these processes. This simulation is solved by

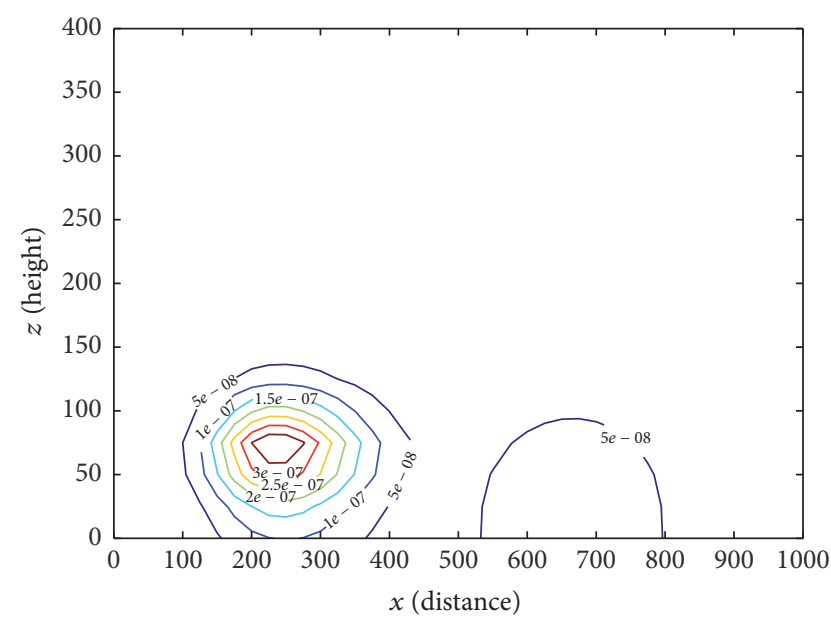

D) Concentration of $\mathrm{SO}_{2}$

FIGURE 7: The concentration levels of air pollution after 1 hour and 36 minutes have passed which are controlled by air quality standard $\left(3 \times 10^{-7} \mathrm{~kg} / \mathrm{m}^{3}\right)$.

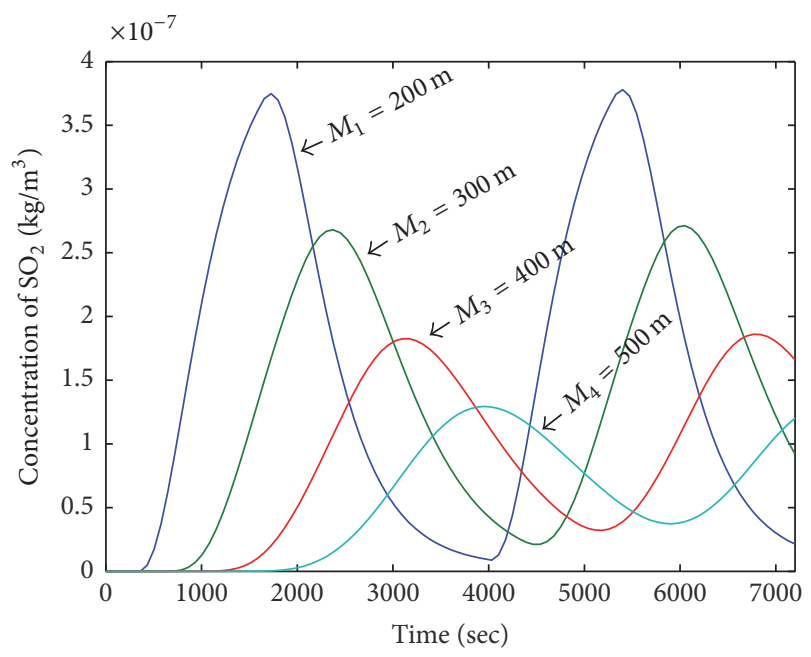

FIGURE 8: The concentration of air pollution with the different monitoring point at $z=50 \mathrm{~m}$ by air quality standard $(3 \times$ $\left.10^{-7} \mathrm{~kg} / \mathrm{m}^{3}\right)$.

using FTCS in (16) with the initial and boundary conditions (6)-(9). In this emission control case, the concentrations of air pollution when 58 minutes and 1 hour and 36 minutes have passed are shown in Figures 9 and 10, respectively. The concentration of $\mathrm{SO}_{2}$ when 2 hours have passed with the different distance is shown in Figure 11.

From Simulations 1, 2, and 3, the concentrations of $\mathrm{SO}_{2}$ at the height $z=50 \mathrm{~m}$ and the distance $x=300 \mathrm{~m}$ (M2) are compared in Figure 12.

\section{Conclusion}

The atmospheric diffusion model to describe the released air pollutant concentration by an industrial plant is proposed. 


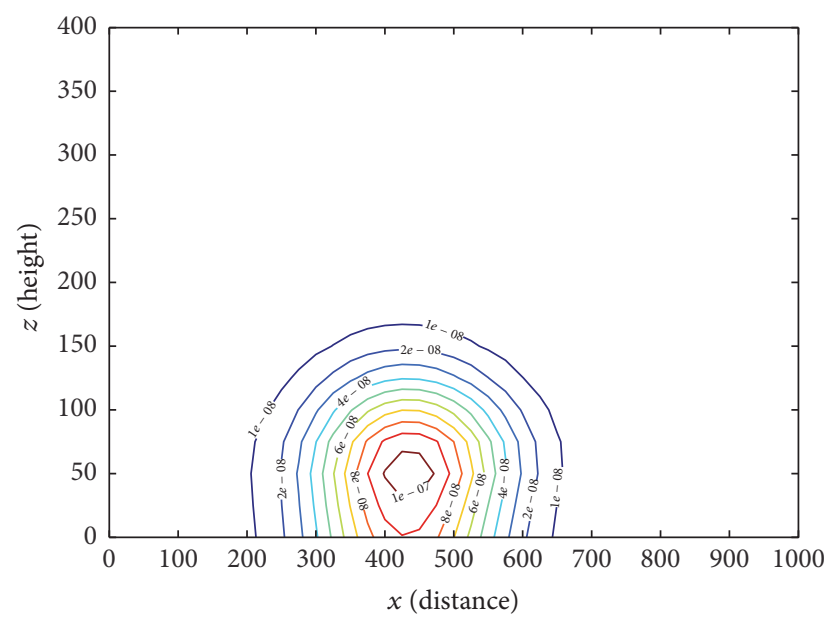

Concentration of $\mathrm{SO}_{2}$

FIGURE 9: The air pollution concentration levels after 58 minutes have passed which are controlled by air quality standard $(1.5 \times$ $10^{-7} \mathrm{~kg} / \mathrm{m}^{3}$ ).

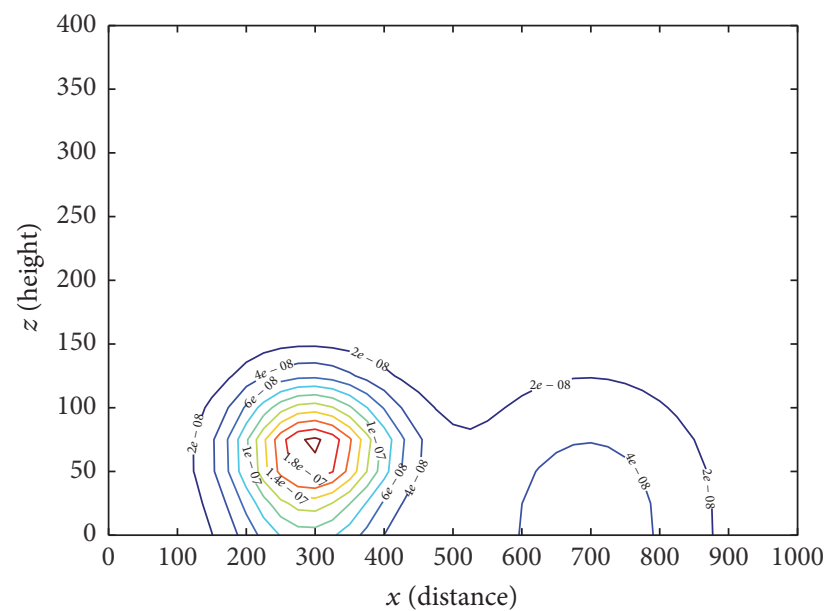

FIgURE 10: The air pollution concentration levels after 1 hour and 36 minutes have passed which are controlled by air quality standard $\left(1.5 \times 10^{-7} \mathrm{~kg} / \mathrm{m}^{3}\right)$.

The concentration of the sulfur dioxide is approximated by an explicit forward time centered space finite difference technique. The method gives good agreement of approximated solutions. The air quality standard near industrial zone is controlled by considering the approximated pollutant concentration levels at all monitoring points. The proposed air pollution controlled simulations demonstrated that the industrial plants need to shut down their chimneys for a while.

\section{Conflicts of Interest}

The authors declare no conflicts of interest.

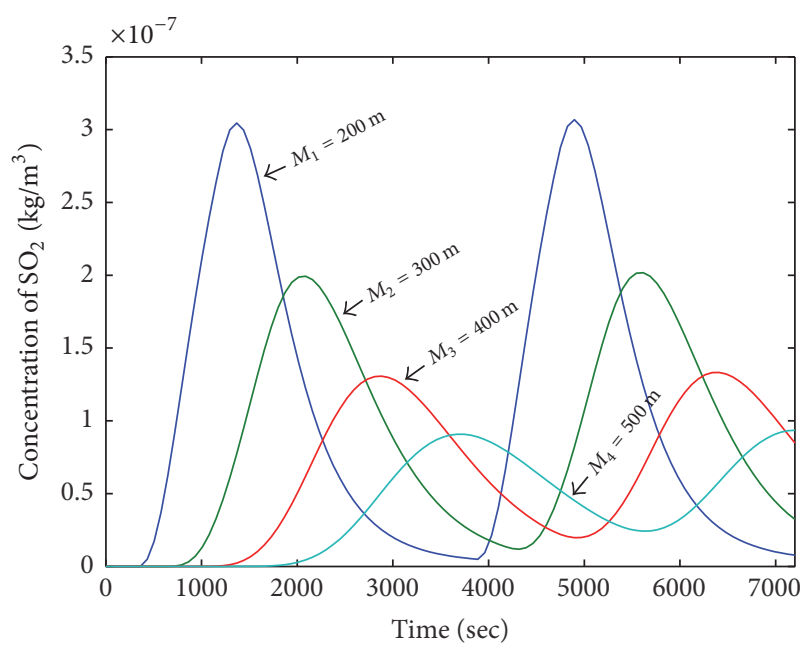

Figure 11: The concentration of air pollution with the different monitoring point at $z=50 \mathrm{~m}$ by air quality standard $(1.5 \times$ $\left.10^{-7} \mathrm{~kg} / \mathrm{m}^{3}\right)$.

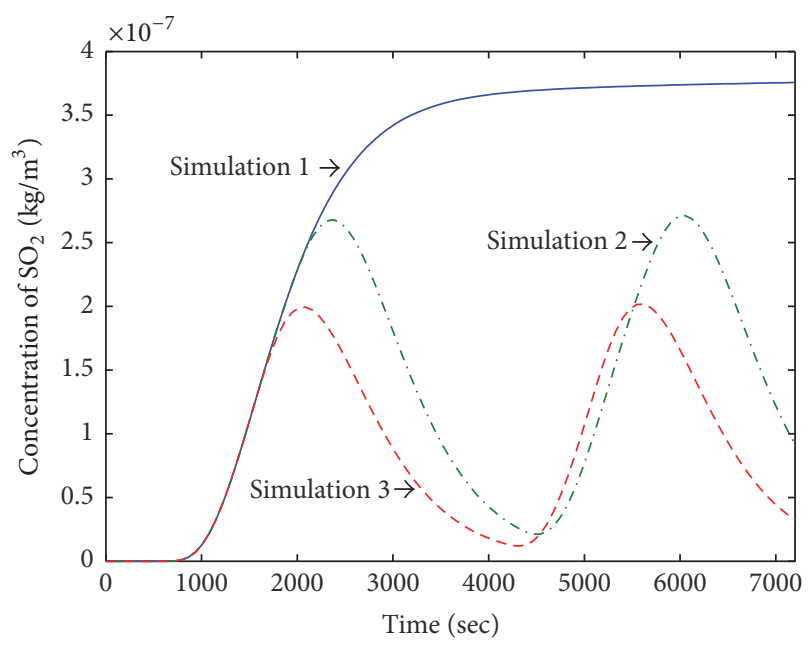

FIGURE 12: The air pollution concentration at $z=50 \mathrm{~m}$ and $x=$ $300 \mathrm{~m}$ (M2) in three cases.

\section{Acknowledgments}

This research was supported by the Centre of Excellence in Mathematics, the Commission on Higher Education, Thailand.

\section{References}

[1] U. Arora, S. Gakkhar, and R. S. Gupta, "Removal model suitable for air pollutants emitted from an elevated source," Applied Mathematical Modelling, vol. 15, no. 7, pp. 386-389, 1991.

[2] J.-S. Lin and L. M. Hildemann, "Analytical solutions of the atmospheric diffusion equation with multiple sources and height-dependent wind speed and eddy diffusivities," Atmospheric Environment, vol. 30, no. 2, pp. 239-254, 1996.

[3] S. A. Konglok and S. Tangmanee, "Numerical Solution of Advection-Diffusion of an Air Pollutant by the Fractional Step 
Method," in Proceedings of the 3rd National Symposium on Graduate Research, Nakonratchasrima, Thailand, 2002.

[4] M. Venkatachalappa, S. K. Khan, and K. A. G. Kakamari, “Time dependent mathematical model of air pollution due to area source with variable wind velocity and eddy diffusivity and chemical reaction," vol. 69, pp. 745-758, 2003.

[5] S. A. Konglok and S. Tangmanee, "A $K$-model for simulating the dispersion of sulfur dioxide in a tropical area," Journal of Interdisciplinary Mathematics, vol. 10, no. 6, pp. 789-799, 2007.

[6] N. Sanín and G. Montero, "A finite difference model for air pollution simulation," Advances in Engineering Software, vol. 38, no. 6, pp. 358-365, 2007.

[7] M. Agarwal and A. Tandon, "Modeling of the urban heat island in the form of mesoscale wind and of its effect on air pollution dispersal," Applied Mathematical Modelling. Simulation and Computation for Engineering and Environmental Systems, vol. 34, no. 9, pp. 2520-2530, 2010.

[8] N. Pochai, "A Finite Element Solution of the Mathematical Model for Smoke Dispersion from Two Sources," World Academy of Science, Engineering and Technology, International Journal of Mathematical, Computational, Physical, Electrical and Computer Engineering, vol. 5, no. 12, pp. 1968-1972, 2011.

[9] S. A. Konglok and N. Pochai, "A numerical treatment of smoke dispersion model from three sources using fractional step method," Advanced Studies in Theoretical Physics, vol. 6, no. 5, pp. 217-223, 2012.

[10] P. S. Kanaroglou, M. D. Adams, P. F. De Luca, D. Corr, and N. Sohel, "Estimation of sulfur dioxide air pollution concentrations with a spatial autoregressive model," Atmospheric Environment, vol. 79, pp. 421-427, 2013.

[11] K. Lakshminarayanachari, K. L. Sudheer Pai, M. Siddalinga Prasad, and C. Pandurangappa, "A two dimensional numerical model of primary pollutant emitted from an urban area source with mesoscale wind, dry deposition and chemical reaction," Atmospheric Pollution Research, vol. 4, no. 1, pp. 106-116, 2013.

[12] K. Lakshminarayanachari, K. L. Sudheer Pai, M. Siddalinga Prasad, and C. Pandurangappa, "Advection-diffusion numerical model of air pollutants emitted from an urban area source with removal mechanisms by considering point source on the boundary," International Journal of Application or Innovation in Engineering \& Management, vol. 2, pp. 251-268, 2013.

[13] M. Vedrenne, R. Borge, J. Lumbreras, and M. E. Rodríguez, "Advancements in the design and validation of an air pollution integrated assessment model for Spain," Environmental Modelling \& Software, vol. 57, pp. 177-191, 2014.

[14] S. M. Kwa and S. M. Salim, "Numerical simulation of dispersion in an urban street canyon: Comparison between steady and fluctuating boundary conditions," Engineering Letters, vol. 23, no. 1, pp. 55-64, 2015.

[15] S. A. Konglok and N. Pochai, "Numerical computations of three-dimensional air-quality model with variations on atmospheric stability classes and wind velocities using fractional step method," IAENG International Journal of Applied Mathematics, vol. 46, no. 1, pp. 112-120, 2016.

[16] United States Environmental Protection Agency, Guideline for Reporting of Daily Air Quality - Air Quality Index (AQI), 40 CFR Part 58, Appendix G, 1999. 


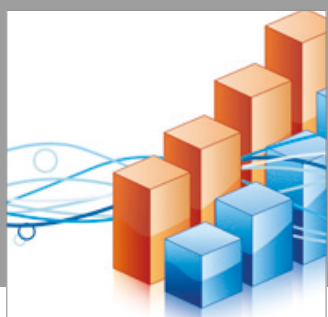

Advances in

Operations Research

vatersals

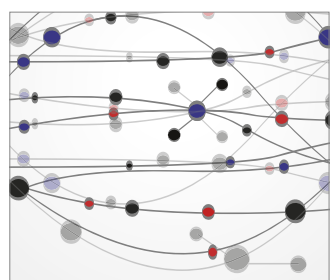

\section{The Scientific} World Journal
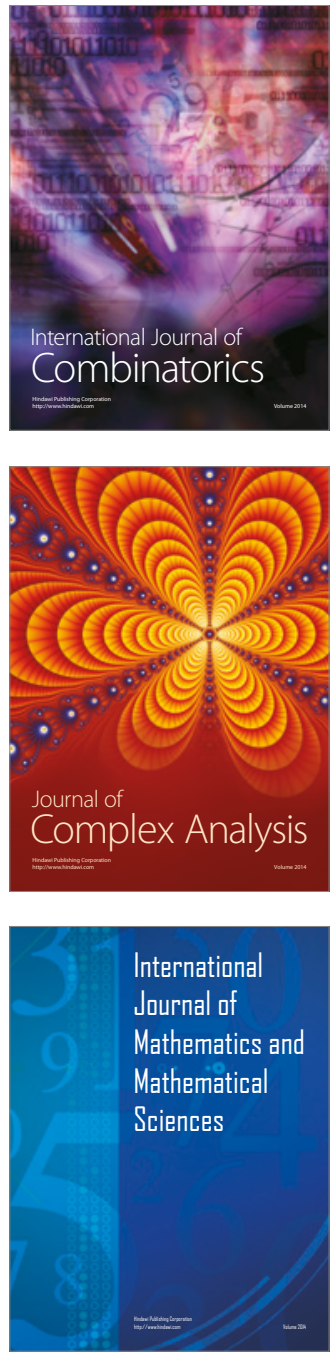
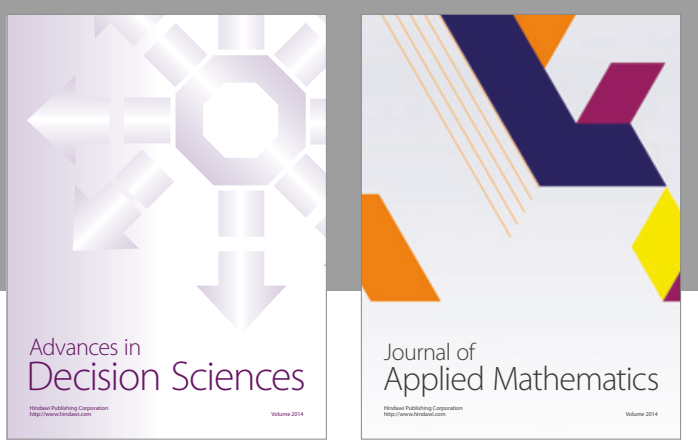

Algebra

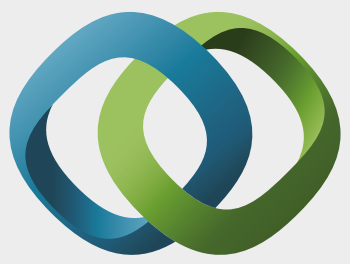

\section{Hindawi}

Submit your manuscripts at

https://www.hindawi.com
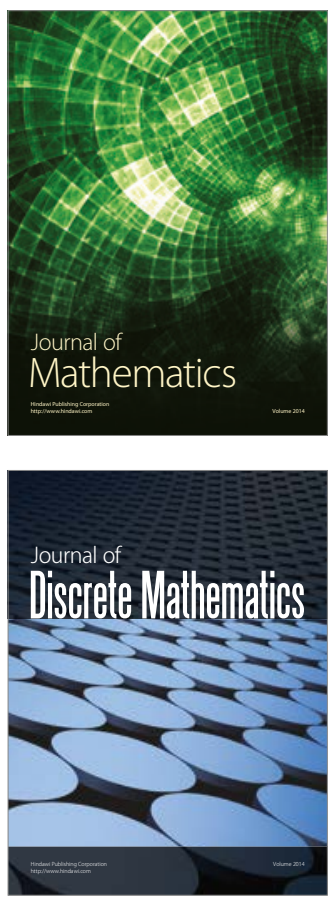

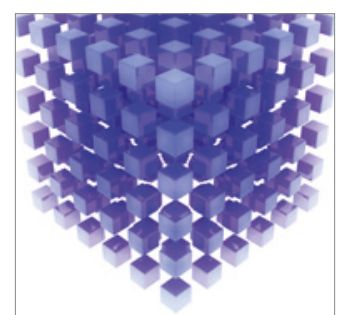

Mathematical Problems in Engineering
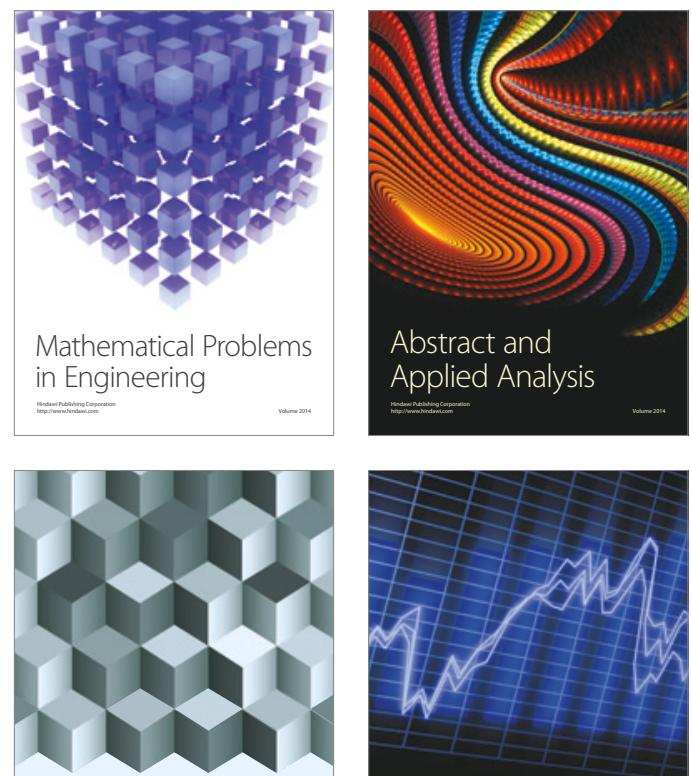

Journal of

Function Spaces

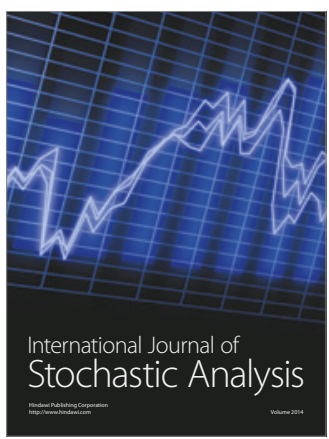

Probability and Statistics
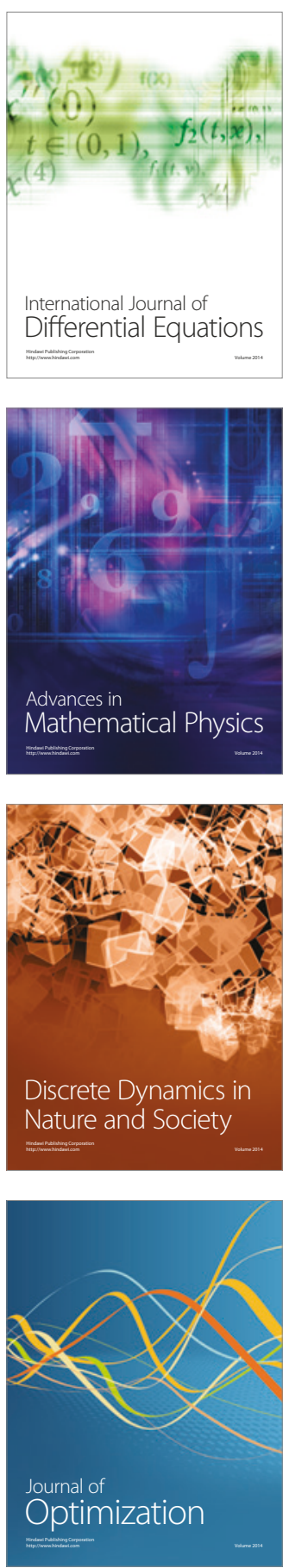